\title{
A Study on the Intention of Tourists Who Visiting Rainbow Village
}

\author{
Kuo-Chung Huang \\ Professor \\ Department of Business Administration \\ Nanhua University, Chiayi, Taiwan \\ Mei-Li Yang \\ Ph.D. Student \\ Department of Business Administration \\ Nanhua University, Chiayi, Taiwan
}

\begin{abstract}
For understanding the intention of tourists who travel Rainbow Village, this research applies the theory of planned behavior to study the tourists' visiting behavior. The questionnaire was distributed and collected in Rainbow village based on a purposive sampling method. The results indicate that the tourists' attitudes, subjective norms, and perceived behavioral control have positive effect on their intention respectively. The construct of attitudes has a complete mediation effect on the subjective norms to the intention. Perceived behavioral control has a partial mediation effect on construct of subjective norms to the intention. According to semi-structure questions result, tourists prefer the authority could provide convenient city bus and friendly restroom as well as children play ground, moreover to keeping genuine painting style help sustainable tourism development of the village.
\end{abstract}

Keywords: Comprehensive Community Development, Intention, Rainbow Village, Theory of Planned Behavior

\section{Introduction}

Base on military village reconstruction, many village houses became run down and face relocation difficulties. Huang Yung-Fu, resident of Taichung Gancheng village knew his house will be tore down, so he painted for memories during his free time for himself even for his neighbors. The pictures are interesting and therapeutic as well as colorful and then Huang was called 'Rainbow Grandpa'( Chao, Cheng \& Yen 2018). Taichung city were requested to preserve the village, and finally the authority planed the designed cultural area and rainbow military community as park space through urban land readjustment. Taiwan has been promoting comprehensive community development for many years, and communities have created eye-catching sightseeing spots through artistic creation. Though Rainbow Village was created by the resident, 'Rainbow Grandpa', how to sustain the paintings has become an important issue to the authority. Many scholars have pointed out that trying to understand the intentions of visit, as well as providing friendly and convenient services, can attract and maintain existing customers and develop potential ones. At the same time, it affects visitors' willingness to revisit or recommend the benefits to others(Brady \& Cronin, 2001; Kim, Ferrin, \&Rao, 2009).

The theory of planned behavior proposed by Ajzen (1985) is a theory derived from rational behavior theory and mainly used to explain and predict people's behavior. The theory of planned behavior indicated that the intentions were influenced by attitudes, subjective norms, and perceived behavioral control. The purpose of this study based on the theory of planned behavior is to investigate the tourists' intention of visiting the Rainbow Village. The research results could help the Taichung city planning the comprehensive community development in the future, and help sustainable tourism development of the village.

\section{Literature Review}

\subsection{Comprehensive Community Development}

The White Paper on Cultural Affairs report by Department of Council for Cultural Affairs, Executive Yuan (2004), the authority presents the comprehensive community development topic and indicates the purpose of the policy. In order to raise peoples' community awareness, to regain people's sense of identity in their own communities, and to jointly improve the quality of community life, the government needs to encourage the residents to participate in comprehensive community development. Moreover, the comprehensive community development emphasizes concept cultivation and training to raise life quality and encourage more residents to concern their hometown through cultural life circuit (Wang, 2016). 
Recently Ministry of Culture (2015) present the community empowerment to establish cultural citizen society and strike a balance culture resource of urban-rural gap. Many communities have begun the plan to promote comprehensive community development, and political support from the government become an important thrust for community development in Taiwan. Many scholars have indicated that the purpose of comprehensive community development is to promote and to improve local cultural environment of communities. Therefore, it is necessary to formulate and implement strategies according to the characteristics of communities themselves, such as improving the living environment of the communities, preserving local cultural or historical materials like monuments, or promoting community arts and cultural activities. (Chang, 2012; Chang, 2015; Chao, 2015; Chu, Tseng \&Sheu, 2006; Hsieh, 2017; Wu, 2003 ).The Rainbow Village story is known around the world and tourists are willing to visit the village. Eventually through the art works, it establishes the community arts and creates business opportunity to local.

\subsection{Rainbow Village}

The Rainbow military housing, recreation attractions of Taichung (2019) is a street art in Nantun District, Taichung. Huang began painting houses in his settlement, now known as Rainbow village, to save them from demolition. Over the years his colorful art, which includes birds, animals, cartoon and people, has spread over the remaining houses in the village, which once contained 1,200 homes. Many houses became run down and developers began buying up the land for redevelopment. Residents were offered compensation or new housing to move but Huang remained ever after his neighbors had left and 11 homes remained only. Local university students discovered Huang's work and campaigned to save the village. Authorities eventually agreed that it should be preserved and hopefully become a designated cultural area. It is a popular tourism attraction, along with nearby Art street pulling in more than a million visitors annually, mostly from Asia. Rainbow village is chosen as the valuable recreation area of Taiwan in Secret marvels of the world which is published by Lonely Planet(Lonely 2017) .

\subsection{Naïve Art}

Rainbow Village is created by Huang who lacks the formal art education and training. This is so called naïve art which is recognized and often imitated, for its childlike simplicity and frankness. You do not have to go to art gallery to appreciate art or attend art activity, and still can explore art works. Art exist everywhere anytime in life (Kanf, 2011). The art works of Rainbow Village represent the local uniqueness and special soft power, which create distinctive brand and achieve community development (Ko, 2016).

\subsection{Theory of Planned Behavior}

The theory of planned behavior indicated that determinant behavior is one's intention to engage in that behavior. The intention is determined by three constructs: attitudes toward the behavior, subjective norms, and perceived behavioral control (Ajzen, 1991).As a general rule, the more favorable the attitudes and subjective norms, and the greater the perceived behavioral control, the stronger should be the person's intention to perform the behavior in question (Ajzen, 2006). Based on theory of planned behavior, some researchers found the attitudes and perceived behavior control of tourists had a significant impact on behavioral intention (Hsieh, Huang, \&Hsu, 2017).In this study, the construct of "attitudes" is defined as assessing the cognition of the tourists about the feelings of visiting Rainbow village, and "subjective norms" is defined as considering how the tourists' family, relatives, friends and others influence on their visits to village paintings locations. And "perceived behavioral control" is defined as evaluating how well the tourists have cognition of their ability to handle their time, financial ability and transportation.

\section{Methodology}

\subsection{Research Model and Hypotheses}

The framework of this study is considered and built basically to explore the tourists' behavior and intention. The structure is following:

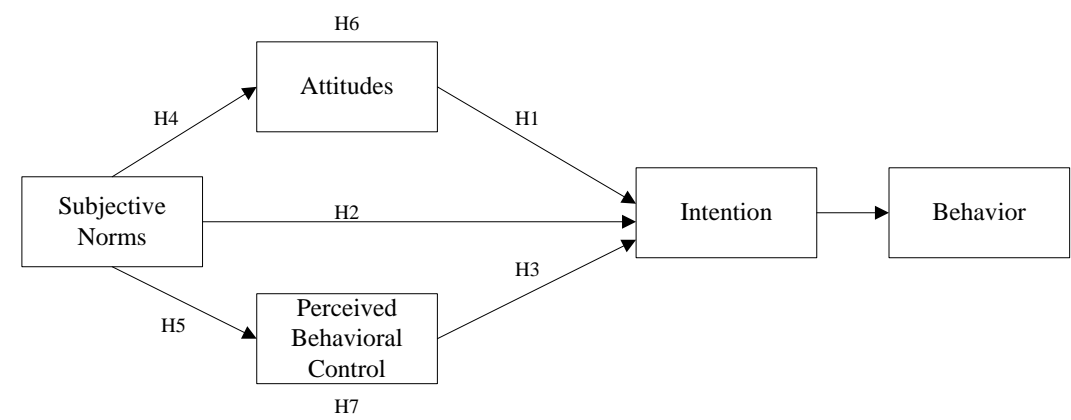

Figure 1 Research Model 
According to the framework, seven hypotheses considered are listed as follows:

H1. Attitudes of the tourists have played a positive role in affecting the tourists' intention to visit the Rainbow Village

H2. Subjective norms of the tourists have played a positive role in affecting the tourists' intention to visit the Rainbow Village

H3. Perceived behavioral control of the tourists 'have played a positive role in affecting the tourists' intention to visit the Rainbow Village

H4. Subjective norms of the tourists have played a positive role in affecting the tourists' attitudes.

H5. Subjective norms of the tourists have played a positive role in affecting the tourists' perceived behavioral control.

H6. Attitudes of the tourists have a mediation effect between tourists' subjective norms and the intention.

H7. Perceived behavioral control of the tourists have a mediation effect between tourists' subjective norms and the intention.

\subsection{Questionnaire Design}

In this research, we try to find multiple tourism dimensions through questionnaire which were contained four constructs. In the construct of "Attitudes", eight items were designed based on four studies (Ajzen, 1991; Blackwell, Engel \&Miniard, 2012; Chu, Tseng \&Sheu, 2006; Hsu, Yeh \& Lin, 2012). In the construct of "Subjective norms", four items were designed based on the works done by some scholars (Ajzen, 1991; Hsieh, Huang \& Hsu 2017; Lin \& Hsieh, 2005;Schiffman\& Kanuk, 2000).Five items in the construct of "Perceived behavior control" were designed based on four studies (Ajzen, 1991; Hsieh, Huang \&Hsu, 2017; Taylor \& Todd, 1995;Wang, 2016). Five items in the construct of "Intention" were designed based on the works by some scholars (Ajzen, 1991;Zeithaml, Berry \& Parasuraman, 1996).The original questionnaire items apply the five-point Likert-type scale to indicate the tourists' agreement or disagreement with the items. The level of agreements in the Likert-type scale utilized responses from 1 to 5, where 1: Strongly Disagree; 2: Disagree; 3: Neither Agree nor Disagree; 4: Agree; 5: Strongly Agree. Meanwhile, the content of the questionnaire also included the source of the tourists, gender, age, education level, number of visits, and transportation method, to collect the demographic information. Additionally, in order to understand the tourists' experience of visiting the painting villages and their suggestions to the authority, there were two semi-structure questions including "Your advice or comment" and "Where are you from". In assessing the reliability of the questionnaire, the Cronbach's alpha was checked. According to Nunnally (1978), standard Cronbach's alpha should be greater than 0.5 , with a coefficient alpha above 0.7 is preferred. In this research, the coefficient alpha of four construct were all above 0.7 , showing that the questionnaires had high reliability.

\subsection{Data Collection}

The questionnaires acquisition was distributed to collect opinions of tourists who visited the Rainbow Village and finally 190 valid data were collected. Among 190 tourists, except Taiwanese there are 62 international friends including Malaysia, HongKong, Japan, Singapore, Thailand and so on.

\section{Analysis and Discussion}

\subsection{Demographic Information}

Finally, 190 valid data were collected in this study.40.5 percent of the respondents were male and $52.6 \%$ were female. 87.8percent of the respondents were under 50 years old. And $73.6 \%$ educational level was above college. $66.3 \%$ responded that it was their first time to visit the Rainbow Village and still have 4.2 percent of the respondents who traveled here above 5 times. And 57.9 percent of the tourists drive by themselves, fewer came and left with public transportation tools. Detailed description statistics related to the respondents' characteristics were shown in Table 1. as following 
Table 1. Demographic Information

\begin{tabular}{|l|l|c|c|}
\hline Item & Answering Options & Frequency & Percent \\
\hline \multirow{4}{*}{ Gender } & Male & 77 & 40.5 \\
\cline { 2 - 4 } & Female & 100 & 52.6 \\
\cline { 2 - 4 } & Transgender & 13 & 6.8 \\
\hline \multirow{5}{*}{ Ege } & $\leqq 22$ years & 36 & 18.9 \\
\cline { 2 - 4 } & 23-50years & 131 & 68.9 \\
\cline { 2 - 4 } & $51-65$ years & 20 & 10.5 \\
\cline { 2 - 4 } & $>$ 65years & 3 & 1.6 \\
\hline \multirow{5}{*}{ Number of visits } & Junior high School & 11 & 5.8 \\
\cline { 2 - 4 } & Senior high School & 39 & 20.5 \\
\cline { 2 - 4 } & College & 108 & 56.8 \\
\cline { 2 - 4 } & Graduate School & 32 & 16.8 \\
\cline { 2 - 4 } & First time & 126 & 66.3 \\
\cline { 2 - 4 } & $2-3$ times & 47 & 24.7 \\
\cline { 2 - 4 } & 4-5 times & 8 & 4.2 \\
\cline { 2 - 4 } & Above 5 times & 9 & 4.7 \\
\hline Transportation of go & City bus & 16 & 8.4 \\
\cline { 2 - 4 } back and forth & Tour bus & 22 & 11.6 \\
\cline { 2 - 4 } & Taxi & 110 & 12.6 \\
\cline { 2 - 4 } & Drive by myself & 18 & 97.9 \\
\cline { 2 - 4 } & Others & & 9.5 \\
\hline
\end{tabular}

\subsection{Factor Analysis and Reliability Analysis}

According to Table 2, it indicates that in this study, KMO values of attitudes, subjective norms, perceived behavioral control and intention are respectively given by $0.879,0.673,0.656$ and 0.794 , each construct's KMO value is greater than0.5, and each construct's Bartlett's test of sphericity is significant, implying that the data are appropriate for factor analysis.

Table2. KMO Value and Bartlett's Test of Sphericity for Each Construct

\begin{tabular}{lllll}
\hline \multirow{2}{*}{ Construct } & \multirow{2}{*}{ KMO value } & \multicolumn{3}{c}{ Bartlett test of sphericity } \\
\cline { 3 - 5 } & & Chi-square & df & Sig.(2-tailed) \\
\hline Attitudes & 0.879 & 715.270 & 28 & $0.000 * * *$ \\
Subjective Norms & 0.673 & 273.024 & 6 & $0.000 * * *$ \\
Perceived Behavioral Control & 0.656 & 278.646 & 10 & $0.000^{* * *}$ \\
Intention & 0.794 & 560.195 & 10 & $0.000^{* * *}$ \\
\hline$* \mathrm{p}<0.05 * * \mathrm{p}<0.01, * * * \mathrm{p}<0.001$ & & \multicolumn{3}{l}{}
\end{tabular}

The results of factor analysis for each construct were shown in Table 3. All the items' factor loadings are greater than 0.5 , with the percentage of variance respectively given by54.764\%,61.644\%,49.268\%,68.390\%. No item should be deleted. To examine the reliability, all the values of Cronbach's alpha were $0.739,0.792,0.873$ and 0.883 all greater than 0.7 , implying a high degree of internal consistency.

Table 3. Results of Factor Analysis and Reliability Analysis

\begin{tabular}{lccc}
\hline \multicolumn{1}{c}{ Construct } & Factor Loading & $\begin{array}{c}\text { \% of } \\
\text { Varianc }\end{array}$ & Cronbach's alpha \\
\hline Attitudes & $0.537-0.834$ & 54.764 & 0.873 \\
Subjective Norms & $0.756-0.823$ & 61.644 & 0.792 \\
Perceived Behavioral Control & $0.590-0.856$ & 49.268 & 0.739 \\
Intention & $0.787-0.858$ & 68.390 & 0.883 \\
\hline
\end{tabular}

Related to attitudes, first of all the tourists appreciate the spirits of Rainbow Grandpa, and indicate the pictures are interesting. Related to subjective norms, the highest influenced factor is firstly that I accept my friend's recommendation, and secondly Internet discussion affect whether tourists want to visit the destination or not. In addition, listen to family's encouragement is important as well. 


\subsection{Means Analysis}

Independent samples $\mathrm{T}$ test was adapted to gender, and for the other demographic items, one-way ANOVA with Scheffe's test of post-hoc comparisons were conducted, which indicate whether the demographic characteristics were very importantly different in statistics for each construct.

For understanding tourists' intention through Means Analysis, the results were shown in Table4. Among the five demographic items, the level of education was significantly related to Subjective Norms. Gender, age and number of visits do not affect apparently. For cognition and subjective norms, the means of the tourists' education level who visit the Rainbow Village, "senior high school" and "college" were greater than that of "graduate school". Most of tourists drive by themselves and fewer choose mass transportation, and tourists with taxi are more than with tour bus.

Table 4. Results of Means Analysis

\begin{tabular}{lcccc}
\hline \multicolumn{1}{c}{ Measure } & Attitudes & $\begin{array}{c}\text { Subjective } \\
\text { Norms }\end{array}$ & $\begin{array}{c}\text { Perceived } \\
\text { Behavioral } \\
\text { control }\end{array}$ & $\begin{array}{c}\text { Behavioral } \\
\text { Intention }\end{array}$ \\
\hline Gender & $\mathrm{N}$ & $\mathrm{N}$ & $\mathrm{N}$ & $\mathrm{N}$ \\
Age & $\mathrm{N}$ & $\mathrm{N}$ & $\mathrm{N}$ & $\mathrm{N}$ \\
Education level & $\mathrm{N}$ & $2>4,3>4$ & $\mathrm{~N}$ & $\mathrm{~N}$ \\
Number of visits & $\mathrm{N}$ & $\mathrm{N}$ & $\mathrm{N}$ & $\mathrm{N}$ \\
Transportation of go & $\mathrm{N}$ & $4>3,5>3$ & $1>3,4>3,5>3$ & $\mathrm{~N}$ \\
back and forth & & & \\
\hline
\end{tabular}

Education level 2: Senior High School, 3: College, 4: Graduate,

Transportation 1: City bus, 3: Taxi, 4: Drive by myself, 5: Others

N: Not Significant

\subsection{Regression Analysis}

The regression analysis indicted the result in Table 5 and Table 6 , the standardized regression coefficient of the construct of attitudes, subjective norms and perceived behavioral control to intention were $0.699,0.459$ and 0.575 respectively. All the results were statistically significant. According to multiple regression, attitudes and perceived behavioral control were statistically significant and the value could cover subjective norms, and therefore the hypothesis of $\mathrm{H} 1 \sim \mathrm{H} 3$ could not be rejected. As a result, the tourists' attitudes, subjective norms and perceived behavioral control positively affect the intention of visit the paintings of Rainbow Village. In particular, attitudes has great effect on tourists' intention than the perceived behavioral control toward the behavior and subjective norms.

Table 5. Mediation Effect Analysis (Mediator: Attitudes)

\begin{tabular}{|l|l|l|l|l|}
\hline \multicolumn{1}{|c|}{ Dependent Variable } & Attitudes & Intention & Intention & Intention \\
\cline { 2 - 5 } Independent Variable & & & & \\
\hline Subjective norms & Model 1 & Model 2 & Model 3 & Model 4 \\
\hline Attitudes & $0.537^{* * *}$ & $0.459^{* * *}$ & & 0.117 \\
\hline $\mathrm{R}$ & & & $0.699^{* * *}$ & $0.636^{* * *}$ \\
\hline $\mathrm{R}^{2}$ & 0.537 & 0.459 & 0.699 & 0.706 \\
\hline adj .R ${ }^{2}$ & 0.288 & 0.210 & 0.489 & 0.498 \\
\hline F-value & 0.284 & 0.206 & 0.486 & 0.493 \\
\hline
\end{tabular}

${ }^{*} \mathrm{p}<0.05, * * \mathrm{p}<0.01, * * * \mathrm{p}<0.001$

Mediation effect of attitudes and perceived behavioral control were examined with respect to criterion proposed by Baron and Kenny (1986). Compare the results given in model 2 and model 4 in Table5, the standardized regression coefficient of subjective norms decreased from 0.459 to 0.117 , after adding attitudes in regression model. Subjective norms were not significantly positive effect on intention in model 4. As a result, the tourists' attitudes have a complete mediation effect on the relationships between subjective norms and intention. Hence, the hypothesis of H4 and H6 was not rejected. 
Table 6. Mediation Effect Analysis (Mediator: Perceived Behavioral Control)

\begin{tabular}{|l|l|l|l|l|}
\hline Dependent Variable & $\begin{array}{l}\text { Perceived } \\
\text { behavioral } \\
\text { control }\end{array}$ & Intention & Intention & Intention \\
\hline & Model 1 & Model 2 & Model 3 & Model 4 \\
\hline Subjective norms & $0.519^{* * *}$ & $0.459^{* * *}$ & & $0.220^{* * *}$ \\
\hline Perceived behavioral control & & & $0.575^{* * * *}$ & $0.461^{* * *}$ \\
\hline $\mathrm{R}$ & 0.519 & 0.459 & 0.575 & 0.604 \\
\hline $\mathrm{R}^{2}$ & 0.269 & 0.210 & 0.330 & 0.365 \\
\hline adj. $\mathrm{R}^{2}$ & 0.266 & 0.206 & 0.327 & 0.359 \\
\hline F-value & 69.321 & 50.090 & 92.626 & 53.818 \\
\hline
\end{tabular}

$* \mathrm{p}<0.05, * * \mathrm{p}<0.01, * * * \mathrm{p}<0.001$

Mediation effect of perceived behavioral control on the relationships between subjective norms and intention was found through analysis. Compare the results given in model 2 and model 4 in Table 6, the standardized regression coefficient of subjective norms decreased from 0.459 to 0.220 , after adding perceived behavioral control in regression model. Subjective norms was significantly positive effect on intention and perceived behavioral control was significantly positive effect on intention as well in model 4. As a result, the perceived behavioral control has a partial mediation effect on the relationships between subjective norms and intention. Hence, the hypothesis of $\mathrm{H} 5$ and $\mathrm{H} 7$ was not rejected.

\section{Conclusions}

The results of regression analysis, factor analysis and reliability analysis in this study showed that the standardized regression coefficient of each constructs to intention from the highest to the lowest were attitudes, perceived behavioral control, and subjective norms. The standardized regression coefficient was respectively given by $0.699,0.575,0.459$, showing that the most important construct of influences on the tourists' intention to visit the Rainbow Village was attitude. The tourists care more about their abilities such as time, rest area and convenience of transportation. We could tell the tourists' cognition that visiting the painting village can increase the time being with family or friends, relieve the pressure in life, and that they were pleasant to stroll around due to well route arrangement. The construct of subjective norms indicated that friends and family would influence the tourists' intention to visit the Rainbow Village. Then furthermore the construct of subjective norms indicated that the reports by mass media and online referrals would influence tourists' intention to visit. The construct of intention showed that if the tourists were satisfied with this journey, they would be willing to visit again, to recommend the painting villages to their relatives and friends, to support Rainbow Grandpa, and to recommend the tour destination on the internet. The suggestions from the important people, the reports by mass media and online referrals have positive influence on the tourists' willingness.

The results of two semi-structure questions showed that most of the tourists appreciate the spirits of Rainbow Grandpa and like his paintings. The suggestions to the Rainbow Village and Taichung city from the tourists indicated that improvement of hardware construction, including adding more toilets, parking lots, rest areas, guiding signs and so on is needed. The other suggestions indicated that keeping the original image of pictures with cultural and creative souvenir, increasing the scope of painting and continuing the spirits of Rainbow Grandpa could improve the depth and breadth of tourism, making tourists feel the visit being much more worthwhile and meaningful.

\section{References}

Ajzen, I. (1985). From intention to action: A theory of planned behavior. In J. Kuhl, \& J. Beckmann (Eds.), Actioncontrol: From cognition to behavior (pp. 11-39). New York: Springer-Verlag

Ajzen, I. (1991). The theory of planned behavior. Organizational Behavior and Human Decision Processes, 50, 179211.

Ajzen, I. (2006). Constructing a TpB Questionnaire: Conceptual and Methodological Considerations. [Online] Available: https://pdfs.semanticscholar.org/0574/b20bd 58130dd5a961f1a2db10fd1fcbae95d.pdf(October 1, 2018)

Ajzen, I., \& Madden, T. J. (1986). Prediction of goal directed behavior: Attitudes, intentions, and perceived behavioral control. Journal of Experimental Social Psychology, 22(5), 453-474.

Blackwell, R. D., Miniard, P.W., \& Engel J. F. (2012). Consumer behavior. Singapore: Cengage Learning Asia, (Chapter 8). 
Baron, R. M., \& Kenny, D. A. (1986). The moderator-mediator variable distinction in social psychological research: Conceptual, strategic and statistical considerations. Journal of Personality and Social Psychology, 51(6), 1173-1182.

Brady, M. K., \& Cronin, J. J. J. (2001). Customer orientation: Effects on customers service perceptions and outcome behaviors, Journal of Service Research, 3(3), 241.

Chang, L. Y. (2015). The Governance Predicament and Construction Strategies of Sustainable Community. The

Degree of Doctor of Philosophy in Department Public Policy and Administration, National Chi Na

University.

Chang, Y. C. (2012). Tourism Development in the Context of Community Empowerment: A Tourism Anthropological Analysis on the Fengtian Community in Hualien. The Degree of Doctor of Philosophy in Institute of Anthropological, Tsing-Hua University.

Chao, Chi-Ming, Huang, \& Wei-Ting (2015) Painted Research Community Loving Environment and Tourism Taking Huwei Township Top Brook Case. Journal of Cultural Enterprise and Management, 13, 57-72.

Chao, Chia-Min, Cheng, S. P. \& Yen, S. T. (2018) Explore the Study of the Influence of Colorpainting on the Community - A Case Study of Haomei-Buidai Township. Journal of Cultural Enterprise and Management, 18 (2), 33-48.

Chu, Li-Chuan, Tseng, Hsiu-mi \&Sheu, Kuen-Feng(2006) Residents' Expectation in Community Empowerment Regarding the Role of Community Builders. Journal of Environment and Management, 7(1), 48-67.

Department of Council for Cultural Affairs, Executive Yuan (2018). The White Paper on Cultural Affairs [Online] Available: http://mocfile.moc.gov.tw/mochistory/ images/policy/2004white_book/index.htm (March 26 , 2018)

Hsieh, C. L. (2017) A Study on the Evaluation Model of Sustainable Management Strategy of Cultural. The Degree of Doctor of Philosophy in Management, College of Management, National Taipei University of Technology.

Hsieh, L. Y., Huang, C. Y., \& Hsu, M. C. (2017) Empirical Study on Tourist Behavioral Intentional Pattern of LiuDui Hakka Cultural Centre. Journal of Sport and Recreation Management, 14(2),1-12.

Hsu, M. C., Yeh, M. J., \& Lin, Y. H. (2012) A Study on Tourists Traveling Behavior Intention Model in Dapeng Bay National Scenic Area- The Verification of Theory of Planned Behavior. Leisure \& Society Research, 6, 1-25.

Kanf, Ti-Chin (2011). Rainbow colors : looking into Huang Yongfu's life and works. Journal of Arts Education, 182, $80-88$.

Kim, D. J., Ferrin, D. L., \& Rao, H. R. (2009). Trust and satisfaction, two stepping stones for successful e-commerce relationships: A longitudinal exploration. Information Systems Research, 20(2), 237-257. DOI: 10.1287/isre. 1080.0188

Ko, I. C. (2016) The Analysis of LocalComprehensive Community Development and Cultural and Creative Industries Policies in Taiwan. Journal of Culture Resources, 10, 1-27.

Lin, Min-Ray \& Hsieh, Yu-Chih (2005) A study on the Developmental Factors of Model Environmental Communities in Central Taiwan. Journal of National Taichung Teachers College. 19(1), 89-113.

Lonely Planet (2017) Secret Marvels of the World : 360 extraordinary places you never knew existed and where to fine them. Malaysia: Lonely Planet Publications

Ministry of Culture (2018), Community Taiwan [Online] Available: https://community taiwan.moc.gov.tw/ (September 27, 2018)

Schiffman, L. G., \&Kanuk, L. L. (2000). Consumer behavior (7th ed.). Upper Saddler River, NJ: Prentice Hall.

Taichung City Government Taichung Travel Net (2019), Rainbow military housing

Available:https://travel.taichung.gov.tw/en-us/Attractions/Intro/881/Rainbow-military-housing (January 11,

2019)

Taylor, S., \& Todd, P. (1995). Decomposition and crossover effects in the theory of planned behavior: A study of consumer adoption intentions. International Journal of Research in Marketing, 12(2), 137-155.

Wang, B. C. (2016) Discussing the Composition of the Cultural Life Circuit through the Local Development Process A Case Study of Da-si Village, Miaoli County Journal of Architecture, 96 109-124.

$\mathrm{Wu}$, Tsung-Chiung (2003) Analyzing Impact Cognitions of Tribe Tourism Development - From the Perspectives of Resident's Participation and Tourism Development Stages. Bulletin of the Geographical Society of China. 31, 13-30.

Zeithaml, V. A., Berry, L. L., \& Parasuraman, A. (1996). The behavioral consequences of service quality. Journal of Marketing, 60(2), 31-46. 